\title{
VIVENDO EM CONTEXTO DE VIOLÊNCIA: O CASO DE UM ADOLESCENTE
}

\author{
Lia da Rocha Lordelo* \\ Ana Cecília de Sousa Bastos" \\ Miriã Alves Ramos de Alcântara
}

\begin{abstract}
RESUMO. Este trabalho integra um estudo longitudinal, explorando nexos entre uma história marcada cotidianamente pela violência doméstica e urbana e a construção social de uma cultura pessoal em um adolescente de 14 anos, o segundo dos três filhos de uma família matrifocal. Apoiou-se em entrevistas semi-estruturadas realizadas em diferentes períodos do estudo. Na análise, caracteriza-se um processo de construção social do envolvimento com a violência (na condição de vítima e de agressor), destacando-se o contexto sociocultural imediato, estruturado por situações adversas como pobreza, conflitos intrafamiliares e sociais e, especificamente, violência, todos estes formando o que se poderia chamar de ecologia propiciadora de atos violentos.
\end{abstract}

Palavras-chave: adolescência em contexto cultural, violência, identidade.

\section{LIVING IN A VIOLENT CONTEXT: THE CASE OF AN ADOLESCENT}

\begin{abstract}
This article integrates a longitudinal study, exploring links between a life story determined by daily confrontation of domestic and urban violence and the personal culture of a 14-year-old boy, the second of three children of a matrifocal family. The study was based on semi-structured interviews, made in different periods of the boy's life. In the analysis, a process of social construction of the involvement with violence (in the condition of victim or agent) is characterized, emphasizing the immediate social context structured by adverse situations such as poverty, intra-family and social conflicts and, specifically, violence; this would, finally, create what we could call an ' ecology that propitiates violent acts'.
\end{abstract}

Key words: development, adolescence in cultural context, violence.

\section{INTRODUÇÃO}

Este trabalho, teoricamente inspirado na abordagem ecológica de Urie Bronfenbrenner, é marcado também pela busca de estratégias de construção de significado culturalmente orientadas, na perspectiva co-construtivista de Jaan Valsiner (1987; 2002). Representa, assim, uma tentativa de análise contextualista, numa área de intersecção dos pensamentos desses dois autores, na linha do que tem sido feito em estudos anteriores (Tudge, 1999), Santos e Bastos (2001), Alcântara (2001). O próprio Valsiner (2000) reconhece essa intersecção, valorizando o fato de que o sistema multinivelado proposto por
Bronfenbrenner (1979/1996) para descrever a ecologia do desenvolvimento permite mostrar como as pessoas se relacionam com seus contextos sociais e a heterogeneidade das direções culturais no interior de cada nível: "O sistema aninhado concebido por Bronfenbrenner nos permite ver as conexões entre diversos níveis de organização das relações pessoaambiente" (Valsiner, 2000, p. 128).

A presente análise faz parte de um estudo longitudinal realizado ao longo de uma década, que incluiu entre seus focos de interesse as estratégias de enfrentamento de condições de risco e proteção de crianças e adolescentes no contexto familiar. Foi analisada a situação particular de um adolescente de

\footnotetext{
* Universidade Federal da Bahia. Bolsista de Iniciação Científica (PIBIC).

Endereço para correspondência: Estrada de São Lázaro, 197. Federação, 40210-730, Salvador - Bahia. E-mail: lialordelo@ hotmail.com

\# Universidade Federal da Bahia, Departamento de Psicologia e Instituto de Saúde Coletiva. E-mail: acecil@ufba.br

II Universidade Federal da Bahia. Mestre em Saúde Coletiva pelo ISC/UFBa. E-mail: alcantaramiriam@ hotmail.com
} 
14 anos, o segundo dos três filhos de uma família matrifocal, residente numa área chamada Vale das Pedrinhas, situada em um bairro popular de Salvador, Nordeste de Amaralina, o qual detém, na cidade, os mais elevados índices de mortalidade por violência. A principal questão que orienta esse estudo é: a partir de situações de confronto com a violência relatadas pelo jovem e por sua família, como os diferentes tipos de violência - urbana, doméstica - se expressam no processo de construção social de uma cultura pessoal?

Sob uma perspectiva ecológica, o sujeito em desenvolvimento está inserido em diversos contextos. Esses contextos são muito mais do que simples ambientes (no sentido da situação imediata que circunda o indivíduo) e, devido à sua complexidade e abrangência, são chamados sistemas, multidimensionados $\mathrm{e}$ organizados em diferentes níveis. O microssistema é aquele mais próximo à pessoa, constituído pelos ambientes que interagem com a pessoa mais imediatamente, e estabelecem com ela um vínculo primário. A família é o melhor e mais conhecido exemplo de microssistema. Enquanto o mesossistema pode ser considerado como tecido que interconecta os microssistemas, o exossistema seriam os ambientes que não estão em contato direto com a pessoa em desenvolvimento, mas que a influenciam mesmo que indiretamente. $\mathrm{O}$ macrossistema, mais amplo, seria o contexto cultural em que a pessoa se insere - os valores, costumes e estruturas institucionais. Do ponto de vista ecológico, é impossível estudar o comportamento do adolescente, por exemplo, e o processo de construção de sua identidade, sem considerar os contextos em que os comportamentos se dão. A mais relevante dimensão do contexto são as interações humanas aí existentes, descritas por Bronfenbrenner como díades (1996). Num microssistema, a díade é considerada seu construtor básico, além de possibilitar a formação de outras interações - tríades, tétrades e assim por diante. Revendo sua teoria através de um modelo bioecológico, Bronfenbrenner e Ceci (1994), postulam que, em suas primeiras etapas, o desenvolvimento humano acontece através dos processos de interações recíprocas descritos acima. Para ser efetiva, a interação deve ocorrer regularmente durante um período de tempo prolongado. Os processos proximais, na revisão bioecológica, não atualizam somente potenciais genéticos mas, no curso da ação, eles também dão a tais potenciais conteúdo substancial através da interação com o ambiente externo.

$\mathrm{Na}$ abordagem co-construtivista de Jaan Valsiner (1987; 2000), são enfatizados os mecanismos de mediação semiótica (ou de construção de significado) presentes na configuração da identidade ou, em outras palavras, na construção de uma cultura pessoal (Valsiner, 1994).

O processo social de construção da personalidade, em contexto cultural, é compreendido por Valsiner (1998) como um processo bidirecional de interdependência, cuja compreensão vai além de modelos causais lineares sujeito/ambiente. $\mathrm{O}$ ambiente social possibilita ao sistema da personalidade se rearranjar de forma singular em cada sujeito (Valsiner, 1998), de acordo com sua cultura pessoal. Por cultura pessoal deve-se entender, para Valsiner, os processos mentais internos e também a externalização imediata desses processos. Com estes recursos, cada sujeito tem a possibilidade de ter reservada para si um certo grau de autonomia sobre o contexto. É desta forma que será possível investigar como se dá a construção social da identidade do adolescente em situação de risco: tanto influenciando como sendo influenciado pelos tipos de violência presentes nos diversos contextos em que se insere.

A adolescência parece ser o período do desenvolvimento em que se vê de maneira mais nítida a formação da identidade. De fato, Erik Erikson (1980) já indicava que a adolescência consiste no próprio processo de formação da identidade. Sprinthall e Collins (1994), ao retomarem essa idéia, defendem ainda que esse processo depende de uma interação com uma espécie de pano de fundo. $O$ que a perspectiva ecológica e a co-construtivista nos propõem é uma "agentização" deste pano de fundo, ou seja, atribuir ao contexto um papel mais ativo, neste caso, na formação da identidade, refutando a determinação reduzida do tipo sujeito/ambiente mencionada anteriormente.

$\mathrm{O}$ adolescente a quem nos reportamos neste artigo é considerado, no contexto social ao qual pertence, como um jovem de atitudes violentas ou agressivas. A violência é um fenômeno que requer uma aproximação conceitual rigorosa, dada sua complexidade e a inevitável carga de intencionalidade que acompanha parte das definições comumente apresentadas. Ristum (2001), ao analisar o conceito de violência de professoras do ensino fundamental, propõe que a violência, enquanto conceito cotidiano, se estrutura em classe (dimensão mais geral, em nível sociológico), modalidade (categoria que leva em consideração "o status ou posição social que as pessoas envolvidas ocupam no momento que ocorre a violência" e o "tipo de questão que foi o pivô da violência" (p. 165)) e forma (categoria que especifica como foi praticada a violência). A autora considera que a análise, para contextualizar adequadamente o 
fenômeno, deve incluir ainda categorias relativas às suas causas (que remetem ao contexto de produção da violência, subdividindo-se em causas contextuais distais e proximais - e causas pessoais) e conseqüências (físicas, sociais e psicológicas).

Essas categorias pressupõem, que a violência e as interações, em nível proximal refere-se à díade professor-aluno são "fenômenos sociais relevantes para a construção da individualidade do aluno, especialmente em um período de desenvolvimento em que a internalização de valores sociais, morais, éticos e religiosos ocorre com maior intensidade" (Ristum, 2001, p. 7).

$\mathrm{Na}$ literatura psicológica, uma solução encontrada para abordar o comportamento violento é a definição de comportamento anti-social. O comportamento considerado anti-social, para Valsiner (1994), só pode ser assim rotulado quando comparado com um comportamento totalmente oposto ao seu- o "prósocial", uma vez que, embora as condutas sejam diferentemente rotuladas, os processos psicológicos que dão origem a comportamentos opostos são os mesmos, apenas externalizados de forma diferente. Torna-se frágil o contraste entre o pró- e o anti-social, desta forma; isto nos reporta à afirmação de Tolan, Guerra e Kendall (1995) de que, diante da variedade de significados das condutas através de diferentes contextos, os programas de intervenção no adolescente devem focar os contextos de desenvolvimento. A análise do comportamento violento ou anti-social deve, portanto, incluir a rede de significações dentro da qual é produzido e reconhecido como tal. Por essas razões, é imprescindível considerar o contexto em que vive o jovem, e, porque a violência e a agressividade se tornam objetos de investigação neste estudo, é necessário, ter em mente que todo ato humano, dentro da sociedade, é culturalmente interpretado (Valsiner,1994).

$\mathrm{O}$ primeiro contexto de produção e reconhecimento do comportamento anti-social é, comumente, a família, seguindo-se a escola e os pares. Patterson, DeBaryshe e Ramsey (1989) traçam uma seqüência desenvolvimental de crianças que se entregam à delinqüência crônica, composta basicamente de 3 passos:

1. a parentagem inefetiva, que resulta em transtornos do comportamento;

2. o fracasso acadêmico e a rejeição de pares, fruto dos transtornos acima;

3. e, resultantes do item anterior, humor deprimido e o envolvimento com pares desviantes.
É fácil observar, no modo como essas etapas são descritas, a agentização do contexto e uma perspectiva desenvolvimental adequada, enfatizando a interdependência entre mudanças no contexto (pessoal, agentizado) e processos de desenvolvimento.

Já Tolan, Guerra e Kendall (1995), revisando a literatura na área, reúnem, em seu artigo evidências de que a agressão na infância pode predizer o considerado comportamento anti-social e agressivo na adolescência, tornando a infância uma época promissora para a execução de uma intervenção sobre condutas violentas.

Faz-se necessária uma definição do contexto à luz dos conceitos estudados dentro do projeto. Será investigado, aqui, um contexto de bastante vulnerabilidade frente à condição de risco. O risco, neste caso, é configurado por fenômenos como a pobreza e o perigo da violência (tanto urbana quanto doméstica). O conceito de risco, entretanto, é de uma complexidade que requer, de acordo com Santos (2000), a compreensão da relação entre indivíduo e contexto na trajetória de desenvolvimento. Esta relação deve ser entendida de forma tal que o risco seja compreendido dentro de um complexo, um sistema que compreenda as interfaces riscoproteção/vulnerabilidade-resiliência. É desta forma convergente com a perspectiva histórico-cultural - que a teoria ecológica entende o risco: enquanto parte de uma rede de interações entre indivíduo e o ambiente nos diferentes níveis do contexto (Santos, 2000). Assim, pressupõe-se, neste estudo, uma perspectiva do risco considerando a todo momento o contexto que ele integra, o significado que o adolescente atribui a eventos de naturezas diferentes e o modo como ele os enfrenta. De acordo com Burak (2001), revisando a literatura latino-americana sobre essa questão, os adolescentes que desenvolvem um estilo de vida de alto risco estão menos aptos a alcançar um nível de desenvolvimento humano e psicossocial satisfatório e mais sujeitos a sofrer de problemas como repetência, evasão escolar e violência. É neste contexto de risco e vulnerabilidade que se constrói a identidade do jovem.

A perspectiva acima esboçada sobre riscoproteção, vulnerabilidade-resiliência é compatível com uma visão ecológica do desenvolvimento humano. Quando se enfatiza a atuação dos processos proximais, cresce também a importância da análise longitudinal de trajetórias de desenvolvimento, cuja direção pode ser predita apenas como probabilidade, escapando a uma concepção linear, estreita, de causalidade. O'Connor e Rutner (1996), em revisão de literatura em língua inglesa sobre mecanismos de risco, reafirmam a importância de estudá-los no desenvolvimento e 
quanto uma análise longitudinal focalizando a mudança intraindividual (como é o caso deste estudo específico) é eficaz em detectar esses mecanismos. Para eles, um estudo longitudinal é bastante adequado para se investigar principalmente o significado de variáveis como idade, transição e desenvolvimento em pesquisas sobre risco (O’Connor e Rutner, 1996).

No caso do presente estudo, se a violência representa adversidade na família, será necessário, para prever seu impacto sobre o desenvolvimento das crianças e adolescentes, focalizar os padrões de enfrentamento (a dimensão "processo", na perspectiva ecológica), adotados naquela família, que podem implicar, no nível da "pessoa", em padrões definidores de resiliência ou vulnerabilidade. A pergunta deste estudo focaliza justamente a maneira como se apresenta o enfrentamento da violência no cotidiano de uma família, e o quanto eles se expressa na trajetória de desenvolvimento de um adolescente dentro desta.

Elabora-se, então, o objetivo específico deste trabalho: a partir de situações relatadas pelo jovem e pela sua família, situações estas em que ele se confronta com a violência, será possível analisar os nexos entre os tipos de violência nos diferentes contextos - microssistema e mesossistema especificamente -, e a construção social da identidade desse adolescente, situando-o na posição tanto de vítima quanto de agressor. Esses nexos contribuirão para a construção da identidade dele e para o seu desenvolvimento psicossocial.

\section{O ESTUDO DE CASO: PROCEDIMENTOS DE COLETA E ANÁLISE DE DADOS}

É possível denominar o estudo de Lucas, nosso jovem, como um estudo de caso. Laville e Dionne (1999) referem-se a esta estratégia de verificação como o estudo específico de um caso, seja ele uma pessoa, grupo ou comunidade, possibilitando ao pesquisador formas de compreensão aplicadas, inicialmente, apenas a seu objeto. Essa impossibilidade de generalização, embora considerada por alguns como uma limitação, descortina, dentro dessa mesma perspectiva, a principal vantagem do estudo de caso: a possibilidade de maior aprofundamento da pesquisa, na medida em que se revele a estrutura qualitativa do objeto. $\mathrm{Na}$ investigação do desenvolvimento humano, os estudos de caso, particularmente quando aliados, como neste estudo, a um recorte longitudinal, têm sido vistos como a perspectiva mais adequada para abordar a natureza processual dos fenômenos nesse campo
(Valsiner, 1987), em que se coloca ainda como prioritária a tarefa de descrever minuciosamente fenômenos psicológicos no contexto da vida cotidiana.

\section{O caso}

Lucas $^{1}, 14$ anos, é o segundo dos três filhos de uma família matrifocal. A mãe, Maria Lúcia (49 anos), trabalha como empregada doméstica mensalista e acumula as funções de cuidador e provedor, uma vez que o pai não contribui para o sustento dos filhos. $\mathrm{O}$ casal se separou quando Lucas tinha dois anos de idade. Atualmente, o filho mais velho, Júnior (15 anos) já trabalha, trazendo alguma renda complementar. Ainda estuda, assim como Lucas e sua irmã mais nova.

\section{A coleta de dados}

Esse estudo se baseia em dados coletados ao longo de diferentes etapas de um estudo longitudinal junto a dez famílias do Vale das Pedrinhas, realizado ao longo de nove anos. No primeiro ano, foram realizadas visitas semanais a cada família. Nos três anos seguintes, as famílias foram ainda visitadas, dentro de um projeto de intervenção em saúde, ampliando-se gradualmente o intervalo entre as visitas (mensais, trimestrais, semestrais). Manteve-se, nos anos seguintes, um acompanhamento anual. No oitavo ano, não houve visitas, retornando-se, no último ano, para uma etapa intensiva de trabalho de campo, ao longo de um semestre. Para a presente análise, fez-se um recorte particular, tomando três momentos distintos, ao longo dos nove anos, e utilizando principalmente entrevistas e observação de campo.

Foram realizadas, no período atual, duas entrevistas semi-estruturadas com o adolescente Lucas, 14 anos, e uma com a mãe, Maria Lúcia. A família, assim como as outras participantes do projeto maior, reside em um bairro popular em Salvador, com altos índices de criminalidade e violência. Foram utilizados também relatos de trajetórias de sua família, 10 anos atrás (no início do estudo), e no período de follow up, há 4 anos. A coleta abrangeu ainda os diários de campo concernentes a esses períodos, o que caracteriza o estudo, além de essencialmente descritivo, como de natureza longitudinal. Outra fonte de dados importante foi um instrumento utilizado em entrevista com o adolescente ainda este ano, avaliando condições de vulnerabilidade e resiliência (Hernandéz, 1996), através de itens que investigam habilidades e atividades de rotina e percepções da família, de sua

\footnotetext{
Estamos utilizando pseudônimos.
} 
própria vida social, da presença da família em sua vida, entre outras questões.

\section{ANÁLISE DE DADOS}

Os relatos utilizados neste estudo podem encaixar-se sob a denominação de narrativas, de acordo com algumas características específicas destas. Para Bruner (1997), a principal característica da narrativa é a sequiencialidade inerente a ela: a narrativa é composta por uma "seqüência singular de eventos, estados mentais, ocorrências envolvendo seres humanos como personagens ou atores" (p.46). A segunda característica seria a presença de uma estrutura interna ao discurso, ou seja, não importa a verossimilhança ou não de um discurso, e sim o seu poder enquanto história. A narrativa como técnica de investigação, algo bastante em voga atualmente em diversas pesquisas, é usada aqui com base nas características já descritas por Bruner (1997).

Para Habermas e Bluck (2000), as narrativas de vida são produtos lingüísticos que seguem regras pragmáticas e sintáticas, contando a vida de uma pessoa, limitados por um contexto social e de tempo. Tal afirmação de Habermas e Bluck (2000) nos remete novamente a Bruner (1997) quando define a narrativa, não apenas enquanto enredo, mas também como um meio de usar a linguagem. As discussões teóricometodológicas sobre narrativas e estórias de vida nos levam, de modo geral, à idéia de que falar sobre si é uma forma de fazer sentido sobre o que se fala e um mecanismo implicado na construção social da própria identidade; Habermas e Bluck (2000), a exemplo disso, assumem em seu artigo uma relação estreita entre lembrar, pensar e narrar. A partir disso, então, tanto os relatos sobre Lucas quanto os que ele faz sobre si mesmo serão utilizados na tentativa de encontrar um sentido para a construção de sua identidade.

Após a seleção de episódios temáticos de violência, estes foram analisados nas seguintes categorias básicas, inter-relacionadas - violência urbana (episódios ocorridos na escola e na comunidade) e doméstica (episódios ocorridos em casa, envolvendo membros da família); e episódios envolvendo o adolescente na posição de vítima (da agressividade do pai, da violência e marginalidade presentes no bairro) ou de agente (na creche $\mathrm{e}$ posteriormente na escola, dentro de casa com a mãe e com os irmãos). A análise de dados, utilizando técnicas de análise de conteúdo, foi direcionada no sentido de observar de que forma os diferentes tipos de violência contribuiriam para a construção da identidade do adolescente e para o seu desenvolvimento psicossocial.

\section{VÍTIMA OU AGRESSOR? UMA IDENTIDADE SOCIALMENTE CONSTRUIIDA.}

Tanto no microssistema (família) quanto nos sistemas mais abrangentes (vizinhança, escola) é possível encontrar elementos dessa construção social de identidade, que supõe uma rede social e um protagonista (Lucas).

Nos contatos com os pesquisadores, o comportamento de Lucas praticamente não apresentava características anti-sociais. Aos cinco anos, era uma criança que se aproximava, fazia contato visual, dava abraços, pedia carrinhos (ou carinho?). A própria mãe narrava que, apesar de danado, ele sempre queria abraços. Aos quatorze, chama a atenção da entrevistadora quando, solicitado a falar do que desejava para si mesmo, expressa desejos que envolvem melhorias para a comunidade, ou para a família.

Em contraste, as narrativas da mãe sobre o comportamento de Lucas acentuam, desde muito cedo, o envolvimento em episódios violentos: em casa, como vítima de atos agressivos do pai, em seguida na creche, já como agressor. Atualmente, aos quatorze anos, a mãe se queixa de seu comportamento agressivo em casa, especialmente em relação à irmã menor.

É necessário considerar essas narrativas no contexto da trajetória de vida dessa família. Maria Lúcia e seus três filhos vivem em uma casa que por muito tempo possuía um único cômodo, ao mesmo tempo quarto, sala, cozinha e banheiro, e que não ultrapassava a razão de 2 × 2,5 m. Recentemente, com a ajuda de amigos da igreja que freqüenta (Testemunhas de Jeová), a família conseguiu "bater uma laje" e construir mais um cômodo.

Os dois irmãos de Lucas são portadores de graves problemas de saúde: Lia, a mais nova, sofre de uma alergia crônica, incurável, que compromete seu crescimento físico, dificulta sua permanência na escola e o convívio com pares, além de exigir grande parte das atenções maternas. Júnior, o mais velho, tem problemas cardíacos que já justificaram uma cirurgia.

Mesmo assim, ele é, desde pequeno, o principal parceiro da mãe nas tomadas de decisão sobre a vida da família e na luta cotidiana, que é intensa. Em ocasiões diversas, a mãe narra para os pesquisadores, diante de toda a família, quanto Júnior a ajuda e lhe é solidário nas preocupações cotidianas; também da 
escola vêm elogios sobre o comportamento solidário de Júnior (divide seu lanche com os colegas, por exemplo). Em nenhum momento, porém, escutamos da mãe referências positivas acerca do papel de Lucas na família, ou sobre expectativas quanto a seu comportamento. A única exigência explicitada para Lucas era a de realizar tarefas domésticas, na ausência do irmão mais velho (que começou a trabalhar fora desde os 14 ou 15 anos).

Os meninos, quando pequenos, sofreram não apenas pela extrema pobreza, mas também pela exposição precoce à violência paterna - especialmente Lucas. Embora separado de Maria Lúcia desde dois anos antes do início de nosso estudo, aparecia ocasionalmente (nunca quando os filhos necessitavam dele) para reivindicar o que considerava como seus direitos de pai e de marido: disciplinar o comportamento dos filhos e contar com a fidelidade da ex-mulher. Para isso, lançava mão da violência física, especialmente se estivesse embriagado.

Maria Lúcia é natural de Santo Amaro da Purificação. Veio para Salvador com 7 anos de idade, dada pela mãe a uma professora que reside na Saúde, em troca da promessa de que esta daria estudo a Maria Lúcia . A promessa não foi cumprida, Maria Lúcia foi maltratada nessa casa, onde trabalhou como doméstica a troco de cama e mesa. Ela relata essa fase de sua vida com profunda tristeza, e um sentimento que se resume na expressão:

"fui dada como se dá um cachorro".

Maria Lúcia não voltou a ver a mãe até a idade de 15 anos, quando fugiu da casa onde estava e voltou para Santo Amaro. Chegando lá, a mãe nem sequer a reconheceu; por falta de alternativa de trabalho, ela acabou voltando para Salvador, onde se empregou novamente em casa de família, até casar-se.

$O$ fato de ter vivenciado uma situação de desamparo extremo como a de ter sido "dada" a uma pessoa estranha pode estar, de alguma forma, associada à tolerância acentuada que Maria Lúcia demonstra em face de maus tratos (como os suportados na convivência com o ex-marido). Por outro lado, apesar da dureza de sua vida, ela tem sua própria casa, administra sua própria família e enfatiza:

\footnotetext{
"Jamais dou os meus filhos. Falo assim em dar eles ao pai, quando aprontam, mas nunca vou fazer isso".
}

O preço que ela paga para exercer sua maternidade de forma digna são suas constantes enxaquecas e uma impotência sofrida quanto aos rumos que as trajetórias de desenvolvimento de seus filhos vão assumindo. Por seu lado, os filhos, ao longo de seu desenvolvimento, assumem também os custos de uma trajetória adversa em tantos aspectos. Júnior, portador de um problema cardíaco evitável caso fosse tratado a tempo, assume precocemente responsabilidades com o sustento da família - indiretamente, através de tarefas domésticas e, diretamente, trabalhando fora; Lia sofre, sobretudo pelas limitações impostas por sua doença; Lucas, único filho fisicamente saudável, ocupa na família um lugar vazio de expectativas e só preenchido pelo papel de filho - problema que o faz se comportar de forma agressiva: "Lucas é minha consumição" - expressão utilizada constantemente pela mãe. Também são constantemente reproduzidas na família as referências a queixas de comportamento agressivo provenientes da vizinhança e da escola.

Tratamos aqui de um processo de construção de identidade que muito pouco traz a voz de seu protagonista. Se nos perguntamos de que natureza é o discurso de Lucas sobre si mesmo, os dados de que dispomos nos remetem a um certo vazio. Lucas fala com fluência sobre a família, sobre os irmãos, sobre acontecimentos no bairro. Silencia sobre si mesmo, como que refletindo essa ausência de expectativas que caracteriza a postura de seus pais em relação a ele. Até os seus desejos, quando expressos, têm um abstrato outro como objeto - a casa, o teto, cercas de arame para o campo de futebol.... No entanto, no desenho que lhe pedimos que fizesse sobre seu futuro, ele projeta para si mesmo uma família: uma casa, dois filhos.

Ao falar sobre si próprio, ele apresenta um discurso pouco entusiástico, talvez mesmo pobre, escasso de informações. Não sabe de suas qualidades com precisão; já de seus defeitos, parece um pouco mais consciente. Descreve-se como "nervoso e orgulhoso", não sabe "perdoar os outros em nada". Essas características podem estar ligadas ao fato de ser considerado pelos outros (família, escola) um garoto agressivo e violento, embora ele não explicite isso em suas palavras.

Sua narrativa, por outro lado, esclarece mais sobre os componentes "de risco" das redes sociais às quais ele vai se integrando. Utiliza-se com bastante familiaridade de palavras típicas de um universo de violência e criminalidade (expressões como cerco, presunto, "olhar"), o que nos faz cogitar sobre até que ponto ele está envolvido na situação perigosa do bairro que relata e da qual se considera vítima - se simplesmente ao ponto de vítima, ou se já enquanto um agente da violência. Alguns meses depois da nossa última visita a Lucas, sua mãe telefonou preocupada, 
pedindo-nos a ajuda de algum profissional especializado $^{2}$. Maria Lúcia explicita claramente, nesse momento, a suspeita de que o filho já esteja envolvido em transações como o tráfico de drogas e, conseqüentemente, com o universo da criminalidade.

Apesar do crescimento acentuado dos índices de violência urbana, temos indicações de que o enfrentamento da violência é algo que, desde muito cedo, compõe o cotidiano dessas famílias, tornando-se por vezes tão cotidiano que até se banaliza e comporta "jogos de cintura", maneiras rotineiras de convivência

A casa de Maria Lúcia, por exemplo, fica numa rua estreita, atrás do campo de futebol. É uma casa de fundos, à qual se tem acesso por um pequeno e estreito beco. Quando a pesquisa começou (Lucas tendo cinco anos), Maria Lúcia tentava proteger esse acesso por um portão de latão, fechado a cadeado. O portão está constantemente fechado por causa dos jogos e outras atividades - brigas, por exemplo - que ocorrem no campo. Mesmo assim, ela conta que alguns "gaiatos" pulam o muro, vindo esconder produtos de roubo ou fumar maconha na porta de sua casa, exatamente por esta ficar escondida.

São dessa natureza, pois, preocupações corriqueiras no cotidiano dessa mãe:

\begin{abstract}
"Quando o carro da polícia vem, todo mundo fica quietinho, quando o carro sai, continua tudo de novo. Eles entram pra qui (indica o beco), eu botei esse portão aí por isso, mesmo assim eles pulam, porque deram pra vir uma turma dia de semana, eles ficam aqui. Quando eu chego tá tudo sujo de farinha, pimenta, um bocado de coisas; e até roubo eles deram pra trazer pra qui, que a moça daí até reclamou que eles tavam com uma sacola, tentando esconder aí no beco, e aí ela reclamou, nunca mais eles trouxeram não, mas de vez em quando vem, ficam fumando aí ( maconha ). E... entram pra qui, precisa às vezes eu sair... quer dizer eu não
\end{abstract}

Vale ressaltar que, ao longo dos nove anos pelos quais se estendeu o estudo, a equipe de pesquisa tomou várias iniciativas no sentido de ampliar os recursos das famílias no enfrentamento de condições de risco, especialmente quanto ao uso da infra-estrutura de serviços de saúde, educação e, nesse caso, de amparo legal para oficializar a separação, o que implicou em limitar a ação violenta do pai. Participávamos no Projeto UNI-Bahia (UFBa, Secretaria de Saúde, Fundação Kellogg), e as famílias foram convidadas a participar de grupos de pais e grupos de adolescentes. Lucas foi atendido durante poucos meses no Serviço de Psicologia da UFBa. Visitamos por várias vezes a creche e a escola tentando mediar conflitos e demos suporte à família quando tentou mudança de escola como uma alternativa. vou reclamar, né? Aí eu peço a eles que aqui tem criança e aqui é abafado, e aí com jeito, pra poder ver se sai. Quando já é um conhecido sai, mas quando é estranho a gente fala, é o mesmo que nada, eles ficam aí. Pra a gente passar, tem que pedir licença, porque eles ficam tudo no beco. Uma moça daqui disse que viu ele entrando aqui devagarinho... É conhecido ele, me chama de tia e tudo. Até é esse mesmo que entra aqui. Porque eles ficam pedindo comida e aí eu digo que não tenho pra dar. Eu não tenho pra dar aos meus filhos, eu vou dar a eles? Aí, acho que eles ficaram chateados, aí ele entrou."

A integração entre recursos pessoais e contextuais direciona a identidade de Lucas para uma imagem predominante de um adolescente considerado violento e agressivo.

“...ele é assim tudo dele é na agressividade, olhe eu só sou chamada na escola de Lucas. O problema é ser agressivo, malcriado e agressivo aí fica até difícil eu conversar com eles." (Maria Lúcia, sobre Lucas aos dez anos de idade).

Descrito pela mãe como seu grande problema desde que era bem pequeno, Lucas aparece, nas situações de violência relatadas, tanto como agressor (na creche, e posteriormente na escola, com outros colegas) quanto como vítima (dos maus tratos do pai, quase sempre ausente; e da vizinhança, extremamente violenta e perigosa). Isso nos remete à afirmação de Tolan, Guerra e Kendall (1995) de que há uma provável relação entre as condutas agressivas na infância e posteriormente, na adolescência.

Os episódios são expressivos. Destacamos um relato da mãe sobre Lucas (agressor e vítima) aos cinco anos, na creche.

"Até me falaram que talvez ele não fique mais na creche porque bate nos meninos, morde... Deu uma dentada na barriga da menina... Ele me disse que a menina bateu na cabeça dele, não sabe? Mas aí eles só falam dele, eu não sei realmente. É desobediente em casa; quando reclamo com ele, começa a gritar e a chutar as coisas. Aí o responsável de lá, o A., disse que se continuar assim, ele vai ter que sair de lá. Eu converso com ele, dei uma surra lá na creche, porque eu penso assim: eu trabalho, já não tem lugar pra ele ficar, e tá lá, né? Então ele não quer ficar, fica procurando briga com os meninos, fica difícil. Os meninos também bate nele, então 
eu não ensino isso a ele, que quando uma criança bate desconte. Mando ele fazer queixa lá no pessoal, mas eles é desses que diz que não pode bater nele que ele desconta. Porque ele é de bater".

É consenso, entre a mãe e a professora, que bater na criança na própria creche, na frente de todos, na escola, é uma solução, o que ilustra a ampla aceitação da punição física como forma de controle disciplinar:

Elisa (professora de Lucas) conta que Lucas é um problema: bate nos colegas, chuta as coisas, xinga os adultos com palavrões. Agora, porém, ele está melhor, segundo Elisa devido à mãe tê-lo castigado (Diário de campo, sobre Lucas aos 7 anos).

A posição de vítima é muito clara, sem dúvida, nos episódios que descrevem como Lucas e seus irmãos foram alvo da violência paterna.

\begin{abstract}
"Mas se disser que eu vou mandar ele pra ficar com o pai, ele não gosta não! Ele chora. Eu disse a ele que se ele sair da creche, quem vai olhar ele é o pai, não é, Lucas? Ele começou a chorar. Mas, não dou não. Porque ele tem uma vida muita errada, eu acho, né? E duas vezes que ele levou as crianças pra ficar com ele, ele deu bebida pros meninos se embriagar" (Maria Lúcia).
\end{abstract}

"Meu pai chegou e me viu brincando na cama, aí fez o que pa mim? Bateu como quê! Aí jogou Lucas em cima da cama" (Júnior, aos sete anos)

Maria Lúcia esclarece esse último episódio, ocorrido cinco anos antes de quando nos é relatado por seu filho mais velho. Quando Lucas era ainda um bebê, o pai se aborrecia se ele chorava à noite, e para impedi-lo de chorar, atirou-o em cima do beliche, e ainda impediu a mãe de ir socorrê-lo; ela teve que esperar o marido adormecer para ir, então, buscar Lucas, cujo nariz havia sangrado. Em outros momentos, o pai colocava o ferro de engomar sob o pé do bebê, para machucá-lo e dessa maneira impedi-lo de agitar as perninhas, coisa que impedia o pai de dormir.

A própria mãe associa os problemas de comportamento de Lucas à violência paterna:

“...eu disse que o pai era agressivo tanto em palavra quanto em ação porque ele espancava, eu achava que aquilo ali não era bater nos filhos, era espancamento entendeu.
Aí ele disse que tudo isso influi no caso de Lucas ser assim..." (Maria Lúcia sobre Lucas aos dez anos).

Tolan, Guerra e Kendall (1995) também sugerem foco sobre as mudanças individuais e a influência das relações interpessoais mais próximas, possivelmente atribuindo ao microssistema uma grande importância no desenvolvimento, principalmente na infância e na adolescência. Lucas parece colocar-se como agente muito mais no que diz respeito às relações interpessoais, ou no que está ao seu alcance (no nível do microssistema): colegas e outras pessoas na escola, irmãos, dentro de casa. No âmbito do que pode ser considerado violência no nível do mesossistema (por exemplo, a violência e criminalidade dentro do bairro), Lucas se descreve sempre como vítima.

\section{E - "Então o maior risco qual é mesmo? \\ L - Ficar por aí dando mole e os cara vir de lá dando tiro, sem saber onde é que vai pegar. Pega em qualquer um que tiver na frente. \\ $\mathrm{E}$ - E você tenta se proteger disso? \\ L - Eu corro logo pra casa de alguém, primeira porta que eu ver aberta eu entro." (Lucas, aos 13 anos)}

Também o discurso de vítima é sempre sublinhado na sua própria fala, enquanto que sua porção agente aparece no discurso de sua mãe o tempo todo, especialmente no período atual. A única parte de sua fala que pode estar relacionada ao fato de ser um garoto bastante agressivo é quando ele se descreve como muito nervoso. Essa descrição de si mesmo foi obtida na aplicação do instrumento avaliador de padrões de vulnerabilidade e resiliência.

Lucas também se pronuncia mais nos episódios em que pode ser considerado vítima da violência urbana, ou no mesossistema. Enquanto agente, especialmente na escola, ele minimiza o que faz, diz que são brincadeiras, nada com o intuito de ser violento ou agressivo. Lucas, desta forma, parece não se enxergar como agente num contexto mais amplo na escola ou no bairro onde vive. Suas características, boas ou ruins, seus desejos parecem se restringir ao microcontexto familiar, onde pode se situar também sua agressividade, relatada por sua mãe: “... a violência do pai de agredir a gente
fisicamente marcou ele (Lucas), ** Ele
agride essa pequenininha aqui [a irmã menor]
que não está fácil, ele chuta, ele belisca, o
que ele pegar. Se ele pegar um * ele joga, se
ele pegar essa tábua ele joga, o que ele pegar 
ele joga nela" (Maria Lúcia, sobre Lucas aos 13 anos)

Impossível não associar este episódio às descrições das formas de agressão praticadas pelo pai contra Lucas quando bebê.

\section{CONCLUINDO}

Observando sua trajetória ao longo do tempo, é possível perceber que, em sua infância, havia mais episódios de violência dentro do microssistema, principalmente aqueles episódios em que o garoto aparecia como vítima, no discurso da mãe. Comparando-se com o momento atual, na sua adolescência, e considerando-se sua própria narrativa, o mesossistema parece ser o contexto que mais o situa na posição de vítima, o que é evidenciado na convivência com a violência e o crime no próprio bairro.

\footnotetext{
“...aí eles começam a briga, por tudo eles brigam. E ELE É DE BATER. Um instantinho que ele sai aí, toda hora vem gente aqui fazer queixa dele: que bateu, que jogou pedra, é assim.. e na creche ele só... mas assim também, é pedra e morder e bater nas crianças..." (Maria Lúcia sobre Lucas aos cinco anos).
}

A análise dos episódios, em seu conjunto, pode indicar que a atitude agressiva de Lucas se dá paralelamente ao fato de ele ser mesmo uma vítima da violência. Esses episódios são mostras de que há um limite tênue entre as posições que Lucas assume agente ou vítima, independentemente do sistema em que esteja inserido. Nesse processo, insinua-se claramente a seqüência de desenvolvimento do comportamento anti-social descrita por Patterson, DeBaryshe e Ramsey (1989).

É possível, a essa altura, pensar na idéia de Valsiner (1998) da construção da identidade como um processo de interdependência. Longe de seqüências lineares que se sucedem e resultam num dado comportamento, o que se encontra é, por um lado, um contexto violento e/ou que propicia a violência; por outro, um adolescente que lida com este contexto através de estratégias singulares, construindo, assim, uma personagem de alguma forma coerente com esses contextos, e evidenciada na família, na escola e na comunidade através de relatos seus e de sua mãe, principalmente. A idéia já exposta de Valsiner (1987; 2000) do comportamento humano construído pelas pessoas em sua transação entre culturas pessoal e coletiva (Valsiner, 1994) também é útil para que se leve em conta que cada ato é denominado anti- ou prósocial culturalmente, o que vale para nos lembrar de que um comportamento nunca pode ser considerado "violento" ou "agressivo" em si, mas culturalmente interpretado (Valsiner, 1994), integrado num contexto. Comportamentos anti-sociais e pró-sociais são culturalmente construídos, e, até certo ponto, definemse mutuamente. Além do mais, essa visão contribui para pensarmos nos aspectos relacionais que compõem a construção social da identidade. Ciampa (1987) afirma a identidade como metamorfose e articulação da diferença e da igualdade. Ele coloca que a identidade não pode ser vista como "mesmice", mas como um contínuo movimento de concretização de si. Isso é importante quando se pensa nas mudanças constantes por que passa um adolescente, influenciadas pelas múltiplas condições - sociais, históricas, relacionais, etc- que o circundam.

Uma compreensão adequada da trajetória de Lucas deve levar em conta os significados em torno de violência prevalentes no seu grupo cultural de referência, o que inclui polaridades como por exemplo as que definem o seu lugar e o lugar de seu irmão mais velho na família. A inserção de cada um dos filhos como membro da família, por sua vez, interage com a trajetória dessa família matrifocal em contexto socialmente adverso, marcado por condições como pobreza, violência e suporte social precário, ausência paterna, sobrecarga materna.

Uma ecologia propiciadora de atos violentos seriam as condições do contexto, em especial do micro ao exossistema, dentro das quais Lucas vem construindo sua identidade do modo tão intimamente ligado à violência - seja ela em que contexto for (doméstico ou urbano), fazendo dele agente, vítima ou ambas as coisas. Sobretudo, condições que delimitam de tal forma as estruturas de oportunidade que a afirmação da identidade e a possibilidade de protagonizar a própria vida podem se tornar possíveis apenas através dos roteiros da violência.

\section{REFERÊNCIAS BIBLIOGRÁFICAS:}

Alcântara, M. A. R. de (2001). Modos do adolescente enfrentar o risco: um estudo longitudinal sobre projetos de vida no contexto da família. Dissertação de Mestrado, Instituto de Saúde Coletiva, Universidade Federal da Bahia, Salvador.

Bronfenbrenner, U. (1996). A Ecologia do Desenvolvimento Humano - Experimentos Naturais e Planejados. Porto Alegre: Artes Médicas.

Bronfenbrenner, U. (1995). Developmental ecology through space and time: a future perspective. In: Phyllis Moen, Glen H. Elder \& Kurt Lüscher (Eds.) Examining Lives in Contex: Perspectives 
on the Ecololy of Human Development. (pp. 619-647). Washington: American Psychological Association.

Bronfenbrenner, U. \& Ceci, Stephen J. (1994). Nature-Nurture Reconceptualized in Developmental Perspective- a Bioecological Model. Psychological Review, 101 (4), 568586.

Bruner, Jerome (1997) Atos de significação. Porto Alegre: Artes Médicas.

Burak, S. D. (2001). Marco epidemiológico conceptual de la salud integral y el desarrollo humano de los adolescentes. Em: Adolescencia y Juventud in America Latina. (pp. 469487) Cartago: LUR.

Ciampa, Antonio da C. (1987). A Estória do Severino e a história da Severina- um ensaio de Psicologia Social. São Paulo: Brasiliense.

Erikson, E. (1980). Infância e sociedade. Rio de Janeiro: Zahar.

Habermas, Tilmann; Bluck, Susan (2000). Getting a life: The emergence of the life story in adolescence. Psychological Bulletin. 126(5), 748-769.

Hernandéz, A. C. (1996). Familia y adolescencia: indicadores de salud. Washington: W. K. Kellog Foundation.

Laville, C. \& Dionne, J. (1999). A construção do saber. Manual de metodologia da pesquisa em ciências humanas. Porto Alegre: ArtMed/Editora, UFMG.

O'Connor, T. G. \& Rutner, M.(1996). Risk Mechanisms in Development: Some Conceptual and Methodological Considerations. Developmental Psychology. 32 (4), 787795.

Patterson, G. R., Debaryshe, Barbara D. e Ramsey, Elizabeth (1989). A developmental perspective on Antisocial Behavior. American Psychologist, 44 (2), 329-335.

Ristum, M. (2001). O conceito de violência de professores do ensino fundamental. Tese de Doutorado não publicada. Faculdade de Educação, Universidade Federal da Bahia.

Santos, M. F. (2000). Com a palavra o adolescente: resignificando trajetórias de risco num espaço de fronteiras. Uma Experiência em Educação para a Saúde.
Dissertação de Mestrado. Instituto de Saúde Coletiva da UFBa.

Santos, M. F. E Bastos, Ana C. de S. (2002). Padrões de interação entre adolescentes e educadores num espaço institucional: re-significando trajetórias de risco. Psicologia: reflexão e crítica, 15 (1), 45-52.

Sprinthall, Norman A.; Collins, W. A. (1994). Psicologia do Adolescente: uma abordagem desenvolvimentista. Lisboa: Fundação Calouste Gulbenkian.

Tolan, P.; Guerra, N.G. \& Kendall, P. C. (1995). A Developmental - Ecological Perspective on Antisocial Behavior in Children and Adolescents: Toward a Unified Risk and Intervention Framework. Journal of Consulting and Clinical Psychology. 63(4), 515-517.

Tudge, J., Doucet, F., Odero, D., Tammeveski, P., Meltsas, M., Lee, S., Kulakova, N. (1999). Desenvolvimento infantil em contexto cultural: o impacto do engajamento de préescolares em atividades do cotidiano familiar. Interfaces: Revista de Psicologia, 2 (1), 23-32.

Valsiner, J. (2000). Culture and Human Development. An Introduction. London: Sage Publications.

Valsiner, J. (1998). The Guided Mind: A Sociogenetic Approach to Personality. Cambridge: Harvard University Press.

Valsiner, J. (1994). Personal Culture and Antisocial Conduct. Trabalho apresentado no XII Congress of Cross-Cultural Psychology, Pamplona, Navarra, Espanha.

Valsiner, J. (1987). Culture and the Development of Children's Action. A Cultural-Historical Theory of Developmental Psychology. Chichester, John Wiley e Sons.

Recebido em 24/04/2002

Revisado em 12/09/2002

Aceito em 30/10/2002 